\title{
Behaviour of Students Towards Electronic Food Delivery Platforms
}

\author{
Mahipal Chandan
}

\begin{abstract}
As the market sees a growth in the electronic food delivery apps services, it becomes important to analyze the market, the consumer behavior and perception towards the service. This will in turn help to understand what the consumer wants. By capitalizing on these findings, the companies can innovate and define new strategies and serve them better. The problem which the researcher studied in the paper was to study the perception, satisfaction and behaviour of college students towards electronic food delivery platforms in Mumbai. In this research, 144 people were surveyed to find out different consumer attitudes of the customers like the loyalty, spending pattern, nutritional intake, the preferred mode of payment. The research would help the various platforms, mainly Zomato and Swiggy to focus on the areas where they are lacking and help them better target the needs of the consumer. It can help them target the new consumers through popular channel. They can know about the consumers preferences with respect to payment options, availability of healthy food and various other aspects.
\end{abstract}

Keywords: Consumer behaviour and perception, electronic food delivery, nutritional intake, Swiggy, Zomato.

\section{INTRODUCTION}

The recent technological growth has been a key factor in the development of many business models and growth of many sectors. It has also created scope for new businesses to arise. One of them being the electronic food delivery app services. This service upon introduction was assumed to face difficulty in adoption by the customers especially in a country like India but the wide and cheap availability of internet across the country and the improved interface provided by the apps has contributed in the increased adoption among customers. The two main players in the industry being Zomato and Swiggy.

One of the advantages of such platforms is that the restaurants that originally did not cater to delivering food to the customers because they did not have drivers can now expand their sales through this platform, also giving customers wider range of options to choose from. Now, the consumers can get their food delivered after comparing menus of different restaurants at their home, place of work or schools by just a few clicks on their smart phones which is a very convenient option. With the rise of nuclear families and

Revised Manuscript Received on May, 2020.

* Correspondence Author

Mahipal Chandan*, BBA Student, NMIMS Anil Surendra Modi School of Commerce, Mumbai, India. Email: mahipalhc@gmail.com

(C) The Authors. Published by Blue Eyes Intelligence Engineering and Sciences Publication (BEIESP). This is an open access article under the CC BY-NC-ND license (http://creativecommons.org/licenses/by-nc-nd/4.0/) the increasing pace of life in the metro cities, ordering food to avoid hassle has become a part of routine of many people in India. Indian electronic food ordering market is set to grow at $16.2 \%$, to touch $\$ 17.02$ billion by 2023 . In this paper the researcher analyzes how the users perceive the food delivery platforms and the consumer behaviour towards these platforms.

\section{LITERATURE REVIEW}

The food and service industry requires the preferences of the customers, to satisfy and identify their needs. According to the research, majority of the respondents were aware about the food apps and the most used apps are Zomato and Swiggy. The respondents considered various factors like delivery time, convenience and good customer service as the most important ones (Vinaik, Goel, Sahai, \& Garg, 2019).

This study analyses the relationship between online food service and the facilities provided and also the factors which influence the buying behaviour of customers. It concludes that as social media has a great influence on customers, it helps the online service providers advertise their products for greater reach to the masses. It also says that as currently, people are in the growth stage regarding the digital world, they prefer cash on delivery as the most convenient option (Kumari, 2019).

The research paper helps to identify the determinants of continuous use intention for food delivery software applications. The research findings stated that the users were influenced by peers, indicating that word of mouth marketing should be pursued by delivery app providers. Hence, it is important for an online service provider to provide several benefits to users so that they do not switch to another delivery app service (Lee, Sung, \& Jeon, 2019).

Recently, as the online food delivery business is growing, this game changing trend of a user-friendly system where orders can be easily placed through a mobile app leads to many challenges that should not be overlooked. It leads to unhealthy patterns of food consumption and has a broader influence on the social environment. Unhealthy low-priced fast food has become a trend as it is easily available (Maimaiti, Zhao, Jia, Ru, \& Zhu, 2018).

Most of the companies nowadays are altering their traditional business strategies into online marketing to meet the demands and needs of the consumers. It is shown that people prefer food delivery apps which provides them offers and promotions. Consumers prefer easy accessibility to food delivery and lower prices and discounts. It is also found that the food misplaces or misuse during transit is a major factor which affects the consumers (Gupta, Roy, Kumar, \& Arora, 2019).

Published By:

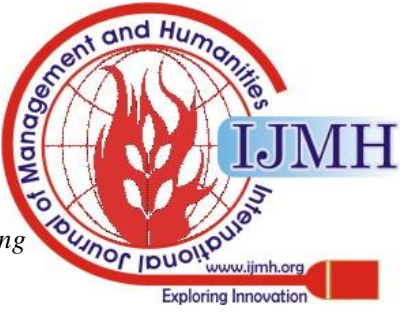




\section{Behaviour of Students Towards Electronic Food Delivery Platforms}

The local vendors are able to connect with people through the delivery apps. According to the findings of the study, most people use online services to avail the offers and discounts available. Majority of the population comes between the age group of 18 to 30 . The average spending by a customer on these apps monthly is approx. $10 \%$ of their income. These apps should increase their reach to local vendors as they are preferred by the customers (Beliya, et al., 2019).

The aggregator delivery services, as opposed to 'Delivery as a Service' companies, generate a platform for consumers to navigate through a variety of restaurants hosted on it and placing orders manually (Bhotvawala, Balihallimath, Bidichandani, \& Khond, 2016).

The research paper helps finding out the customers perceptions and knowledge of electronic food ordering that influences their buying decisions. It analyses the channel that is used more frequently in electronic food ordering. It helps understand customer's perception towards Electronic food ordering. The respondents were more satisfied with online food ordering than ordering from telephone. The findings indicate that restaurant operators should particularly focus on giving their customer convenience (Joao Chorneukar, 2014).

The research helps find various strategies used by major food delivery companies to promote their business in India and the effect caused by online food delivery apps on restaurant business. According to the study, food ordering through apps is growing but still many new start-ups failed to survive in the competition and faced closure (Malhotra \& Singh, 2020).

The research involves finding out the factors which influence the consumers to not switch from one food delivery provider to another provider of online food delivery applications. The research helped to gain in depth information about various parameters of online food delivery application that the consumers expect. The factors that influence the customers to not switch from provider of online food delivery application are offers, web openness that availing the services. This would make the customer believe that they are very important to the company (M P \& Vivek, 2019).

\section{RESEARCH PROBLEM}

The research problem at hand is to study the behaviour of students towards electronic food delivery platforms in Mumbai.

\section{RESEARCH OBJECTIVES}

The objectives of this study are as follows:

1. To understand consumers' attitude and perception towards electronic food delivery platforms.

2. To study the spending patterns of the consumers via the electronic food delivery platforms.

3. To study the loyalty of consumers towards the electronic food delivery platforms.

4. To study the demand drivers of online food ordering and understand the top motivations for the consumers to order food online.
5. To study the consumers' nutritional intake due to ordering food via the electronic food delivery platform.

\section{RESEARCH METHODOLOGY}

A. Research Design: A descriptive research was done to study the consumer perception, satisfaction and behaviour towards the electronic food delivery platforms. Further, their saving patterns were also studied. A cross-sectional study was conducted wherein the data was collected from the respondents only once at the particular time period.

B. Sampling: Primary data was collected from a sample size of 144 respondents (18-24 years of age) from Mumbai during the period of March, 2020. Additionally, the Sampling Method used was Non-Probability Sampling Method as not all elements from the population has equal opportunity of being selected as the sample for the research conducted. Under Non-Probability, Convenience Sampling Method was used as the respondents were selected as per the convenience of the researcher.

C. Data Collection: A Structured Questionnaire was used to collect data from the respondents. The questionnaire consisted of closed-ended questions while the questionnaire was filled by the respondents via Google Form. Secondary information taken from journal research papers.

D. Data Analysis: For the descriptive Analysis, Measures of Central Tendency i.e. Mean, Median and Mode have been used on the data collected through the primary research with the use of Microsoft Excel.

\section{FINDINGS}

A. Objective 1: To understand consumers' attitude and perception towards electronic food delivery platforms.

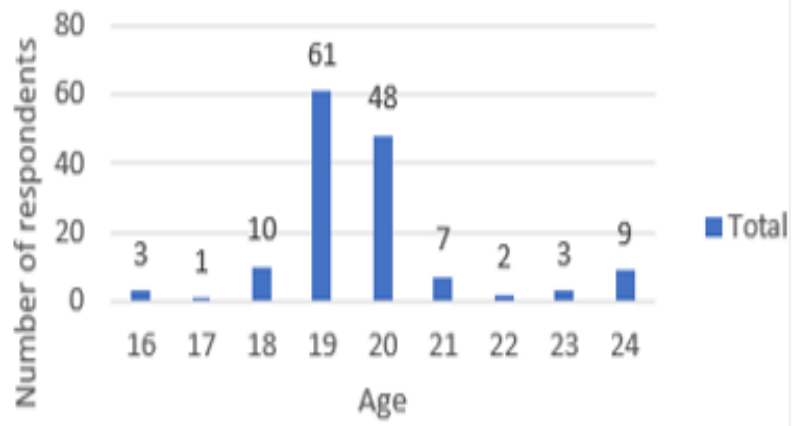

Figure 1.1: Age of Respondents

Observation: In terms of age, a majority of the respondents lie between the age of 19 and 20 years.

Published By:

Blue Eyes Intelligence Engineering 
Table 1.1: Number of respondents using electronic food delivery platforms

\begin{tabular}{|c|c|}
\hline Response & $\begin{array}{c}\text { Count of Do you order } \\
\text { food from online delivery } \\
\text { apps? }\end{array}$ \\
\hline No & 8 \\
\hline Yes & 136 \\
\hline $\begin{array}{c}\text { Grand } \\
\text { Total }\end{array}$ & $\mathbf{1 4 4}$ \\
\hline
\end{tabular}

Observation: From the total of 144 respondents 136 of them use electronic food delivery platforms. This shows that a majority of the people order food online.

Most of the respondents who do not order food online are concerned about the food quality, some do not trust the platforms, some need more customization to be available and the rest feel that the delivery is expensive.

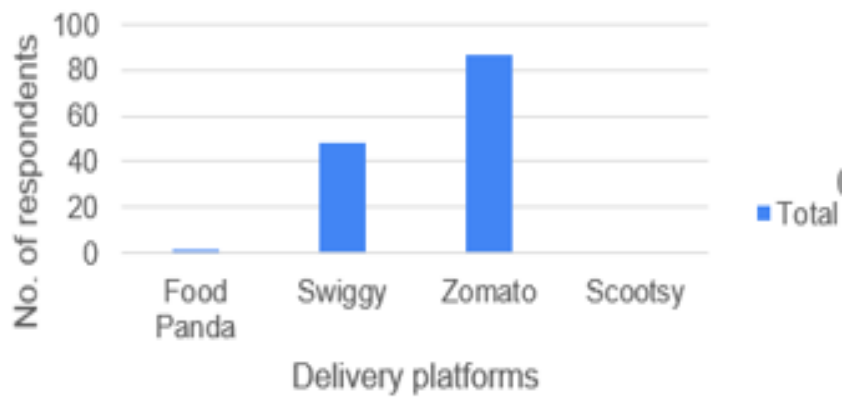

Fig. 1.2: Popularity of food delivery platforms

Observation: Zomato is the most popular among the respondents followed by Swiggy. The rest of the platforms can not keep up with these two platforms and most of them have gone out of business. Food Panda and Scootsy are the other companies which are hanging on.

Out of all respondents who ordered online, i.e. 136 respondents, around $42 \%$ of them were made aware of the platforms through friends and family, around 31\% through advertisements, $26 \%$ through the internet and the rest of $1 \%$ through newspapers.

Out of all the respondents, about 52\% prefer going out for dinner and the rest prefer ordering in.

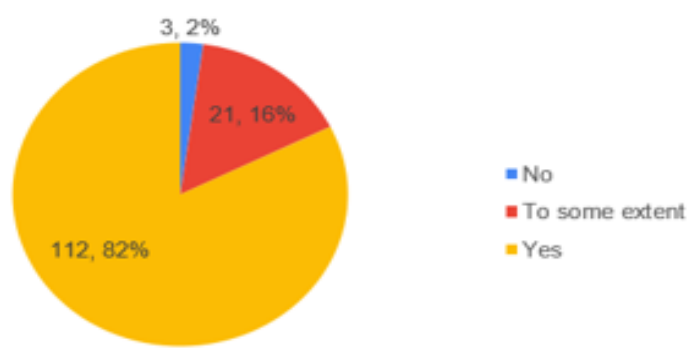

Fig. 1.3: Convenience in ordering online.

Out of all, $82 \%$ respondents find it convenient to order food online, $16 \%$ find it convenient to some extent and the rest find it inconvenient. Around $87 \%$ prefer to order dinner, roughly $12 \%$ prefer ordering lunch and only around $1 \%$ prefer ordering breakfast. Around 59\% of the respondents believe that Zomato provides the best customer service and discounts than any other platform. Roughly $40 \%$ believe it to be Swiggy and the remaining $1 \%$ say it to be Scootsy and Food Panda.

B. Objective 2: To study the spending patterns of the consumers via electronic food delivery platforms.

On an average, the respondents ordered food 3 times a week and spent approximately 500 per order. Hence, with the help of measures of central tendencies, it is calculated that the respondents spend roughly ₹1500 per month and ₹6000 per month.

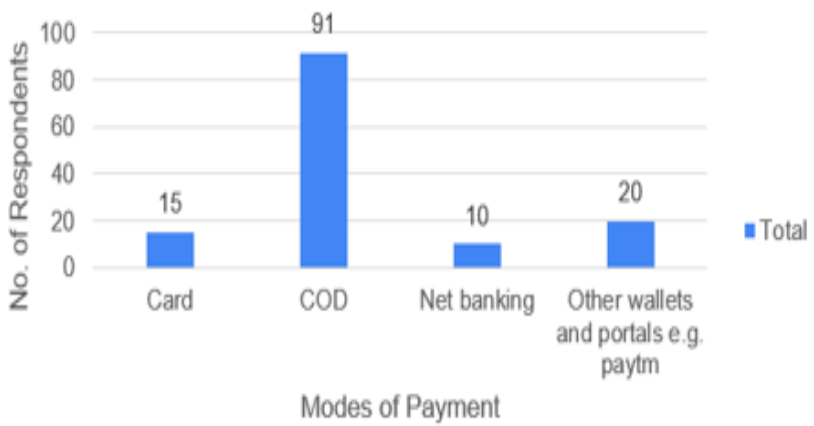

Fig. 2: Preferred mode of payment

Out of all the respondents, around 67\% preferred Cash on Delivery (COD), 15\% preferred other wallets and portals, around $11 \%$ preferred card payments and around $7 \%$ preferred net banking.

C. Objective 3: To study the loyalty of consumers towards the electronic food delivery platforms.

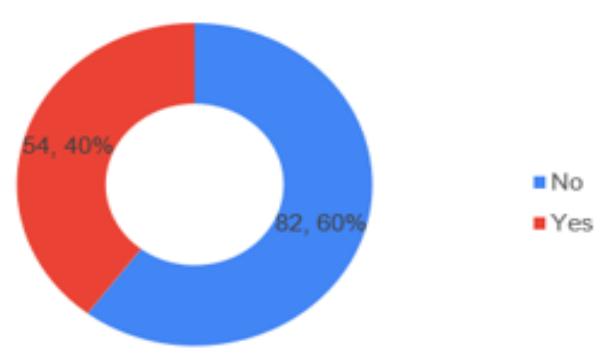

Fig. 3.1: Loyalty of consumers

$60 \%$ of the total respondents answered they were not loyal to their preferred food delivery platform.

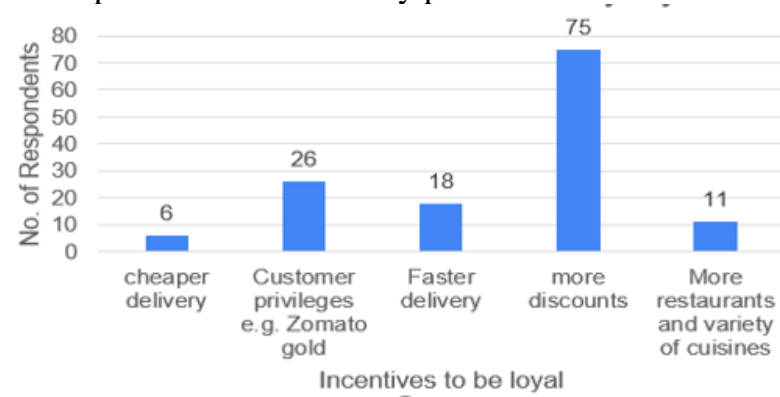

Fig. 3.2: Incentives required to remain loyal

Observaton: Around 55\% respondents would prefer more discounts to remain loyal, 19\% would prefer customer privileges such as Zomato Gold, 13\% prefer faster deliveries and the rest would prefer cheaper delivery charges and the variety of cuisines available.

Published By: Blue Eyes Intelligence Engineering \& Sciences Publication (C) Copyright: All rights reserved. 


\section{Behaviour of Students Towards Electronic Food Delivery Platforms}

D. Objective 4: To study the demand drivers of online food ordering and understand the top motivators for the consumers to order food online. The average rating for discount out of 5 by all 136 respondents was 4, making it the biggest demand driver. It was followed by customer service with 3.83, choice of restaurants with 3.79, delivery time with 3.72 and cash on delivery with 3.37 .

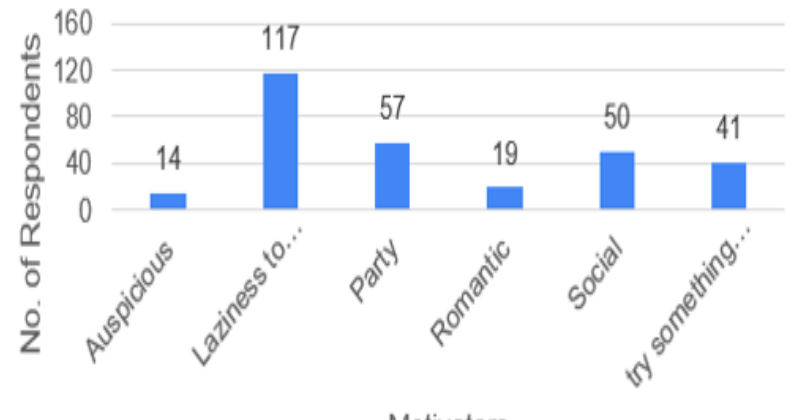

Motivators

Fig. 4: Motivators for ordering online

According to the survey, laziness to go out or cook is the top reason for ordering online, followed by parties, social gathering/events, urge to try something new and auspicious events.

E. Objective 5: To study the value of consumers' nutritional intake due to ordering food via the electronic food delivery platforms.

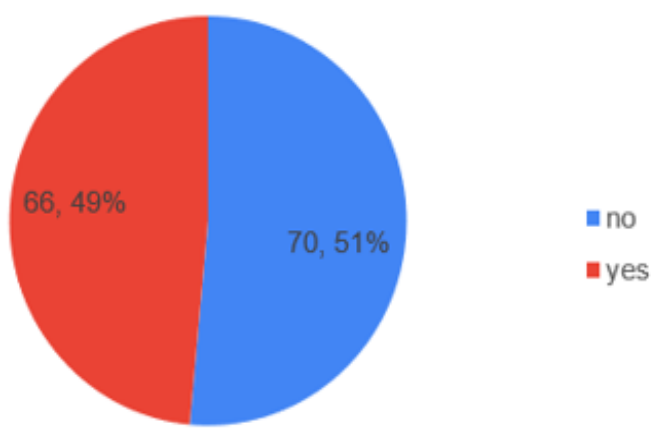

Fig. 5.1: Preference of healthy food

Nearly 51\% respondents do not prefer ordering food online.

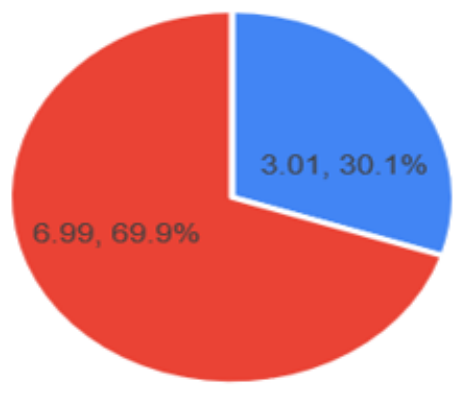

- average no. of healthy orders = Remaining

Fig. 5.2: Average number of healthy food orders
On an average, out of the total orders that the respondents place online, only $30.10 \%$ of the orders consists of healthy food and nutrients.

\section{CONCLUSION}

The primary research was conducted with the help of a survey consisting of a structured questionnaire. The questionnaire was filled by 144 respondents from Mumbai via Google Forms during the period of March, 2020.

A majority of the sample lied in between 19 and 20 years of age. Additionally, 136 out of the 144 (94.44\%) respondents ordered food through the online food delivery platforms. Only 8 respondents (5.56\%) did not order food online the major reason being food quality concerns followed by lack of customization, lack of trust in the app and expensive delivery.

Out of the 136 respondents who ordered food online, 87 respondents preferred Zomato, followed by Swiggy which was preferred by 48 respondents, Food Panda by 1 respondent and Scootsy was preferred by none. This showed how much better and popular Zomato is among the respondents. Also, it showed that Zomato and Swiggy hold a duopoly in the industry.

The respondents were made aware about these platforms mainly through friends (41\%), followed by information through advertisements (31\%), through the internet (27\%) and the remaining through newspapers. $52 \%$ of the respondents preferred to go out whereas $48 \%$ preferred ordering food at home showing potential in the online food delivery industry. A majority of the respondents found it easy to order online Around 82\% of the respondents find it easy to order food online, $16 \%$ find it convenient to some extent and only $2 \%$ find it difficult.

Overall, the online food delivery industry has a lot of potential. Consumers know about the platforms and a majority find it very convenient to order it online and almost $50 \%$ would prefer ordering it online. There is tough competition in the industry which will eventually benefit the consumers.

On an average the consumers spent around ₹6000 per month on food ordered online. Preferred mode of payment was Cash on Delivery, followed by other wallets and portals, debit/credit cards and net banking.

Around 59\% of the respondents found Zomato's customer service and discount schemes better compared to the rest of the platforms. It was followed by Swiggy.

$60 \%$ of the respondents were not loyal to the preferred delivery platform. 55\% of the total respondents would want more discounts as an incentive to stay loyal, $20 \%$ wanted customer privileges, followed by faster delivery and lastly, cheaper delivery.

Discount was a major demand driver with an average rating preference of 4 out of 5 , followed by customer service, delivery time and cash on delivery option.

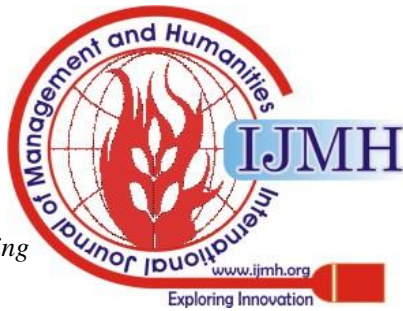


The major motivations for customers to order online was the laziness to go out/cook followed by parties, social gathering, to try new cuisines, romantic purposes and auspicious occasions.

Nearly $51 \%$ of the respondents did not prefer ordering healthy food online. On an average only around $30 \%$ of all the orders of the respondents consisted of healthy food.

The consumers are hardly loyal to the delivery platforms during this period of intense competition. They prefer more discounts which would attract them to the platforms more. It is really beneficial for the consumers to get the benefit of the fierce competition. Feeling lazy to go out/cook is the major reason why the consumers order the food online since they find it very convenient.

All in all, the research showed that the consumer perception towards the online delivery industry is positive and they are quite satisfied. Behaviour towards the industry is quite positive.

\section{RECOMMENDATIONS}

1. The companies should try to build more trust in the consumers who are not ordering online by improving quality and raising their standards.

2. The companies should try making their applications and websites more user friendly and easy to use.

3. The companies can tie up with various payment applications and portals to offer the customers with various benefits if paid via those portals. This may benefit both the sides and increase business.

4. The companies can introduce loyalty programs and offer various benefits to loyal customers. This will help prevent competition.

5. Discounts are preferred by the consumers and the companies should find out unique ways to offer better discounts than the competitors and also, not make losses while doing so.

6. The companies should advertise in a way which would entice the lazy consumers to order online. They can also target various events and occasions and offer discounts during festivals in India.

7. Various consumers are keen on ordering healthy food but end up not ordering such food. Companies can try to get on board restaurants that offer healthy food to the consumers.

\section{SCOPE/LIMITATIONS OF THE STUDY}

1. The scope of the study is limited to Mumbai only. No other city is studied in this research.

2. The primary research is limited to a sample size of 144 respondents. Hence, the findings may not be the true representatives of the entire population.

3. The age of the sample is 18-24 years; therefore, the findings may not hold true for different age groups.

4. The research was conducted in the period of March,2020. The findings may be true to that period only.

\section{APPENDIX}

Questionnaire:
Greetings! This research is being conducted by students of NMIMS, Mumbai in order to understand the consumer behaviour towards Online Food Delivery Platforms. We request you to fill the questionnaire given below.

Thank you for your time and consideration.

* Required

1) What is your age? *Mark only one.
16
17
18
19
20
21
22
23
○ 24

2)Do you order food from online delivery apps? * Mark only one.

- Yes (Skip to question 4)

- No (Answer only question 3 and end your survey)

3) Why do you not order on online food delivery platforms?

* Mark only one.

○ Delivery is expensive

$\circ$ Difficulty in placing order

○ Lack of trust in the app

○ Food quality concerns

- Lack of customization

4) Which application do you use to order most often?

* Mark only one.

- Zomato

○ Swiggy

- Food Panda

- Scootsy

5)How did you get to know about the platform? *Mark only one.

○ Friends \& family

- Advertisements

o Internet

○ Newspaper

6) What would you prefer?

* Mark only one.

○ Going Out

○ Ordering at home

7) Is it convenient and easy to order via these online food platforms?

* Mark only one.

○ Yes

○ No

○ To some extent

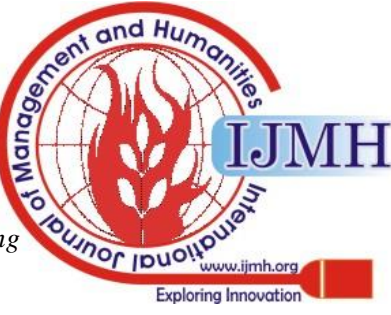




\section{Behaviour of Students Towards Electronic Food Delivery Platforms}

8) When do you order the most?

*Mark only one.

○ Breakfast

○ Lunch

○ Dinner

9) How many times do you order food online in a week?

*Mark only one.
$\circ \quad 0-2$
○ $3-5$
○ $6-8$
$\circ$ more than 8

10) On an average, how much do you spend per order?

*Mark only one.
○ $0-500$
500-1000
- 1000-1500
○ 1500-2000

11) Mode of payment

*Mark only one.

o COD

- Net banking

- Card

- Other wallets and portals e.g. Paytm

12) Which application has better customer service? *Mark only one.

○ Zomato

○ Swiggy

- Food Panda

- Scootsy

13) Which application provides better discount? *Mark only one.
o Zomato
○ Swiggy
- Food Panda
- Scootsy

14) Are you loyal to your preferred food delivery app even if the other platforms have better offers at the time?

*Mark only one.

o Yes

○ No

15) What would keep you loyal?

*Mark only one.

- More discounts

○ Customer privileges e.g. Zomato Gold

- Faster delivery

- Cheaper delivery

- More restaurants and variety of cuisines

16) What affects your choice of food provider? (5 being most important and 1being the least important)

*Mark only one per row.

\begin{tabular}{|l|l|l|l|l|l|}
\hline Options & 1 & 2 & 3 & 4 & 5 \\
\hline Discounts & & & & & \\
\hline Delivery Time & & & & & \\
\hline Cash on Delivery & & & & & \\
\hline $\begin{array}{c}\text { Choice of } \\
\text { restaurants }\end{array}$ & & & & & \\
\hline Customer Service & & & & & \\
\hline
\end{tabular}

17 ) On what occasion do you order food online? *Check all that apply.

○ Party

○ Auspicious

○ Romantic

- Social

○ Laziness to go out/cook

- Try something new

18) Do you prefer ordering healthy food?

* Mark only one.

○ Yes

○ No

19) Out of 10 times that you order food, how many times is it healthy? E.g. salads

*Mark only one.
○ 1
$\circ 2$
○ 3
$\circ 4$
$\circ 5$
○ 6
○ 7
○ 8
○ 9
○ 10

\section{REFERENCES}

1. A. Vinaik, R. Goel, S. Sahai and V. Garg, "The Study of Interest of Consumers In Mobile Food Ordering Apps," International Journal of Recent Technology and Engineering, vol. 8, pp. 3424-3429, May 2019.

2. V. K. Kumari, "An Impact of Consumer Behavior Towards Online Food Services," International Journal of Recent Technology and Engineering, vol. 8, no. 1C2, pp. 497-499, May 2019.

3. S. W. Lee, H. J. Sung and H. M. Jeon, "Determinants of Continuous Intention on Food Delivery Apps : Extending UTAUT2 with Information Quality," Sustainability, 2019.

4. M. Maimaiti, X. Zhao, M. Jia, Y. Ru and S. Zhu, "How we ea determines what we become : opportunities and challenges brought by food delivery industry in a changing world in China," European Journal of Clinical Nutrition, pp. 1282-1286, April 2018.

5. R. Gupta, S. Roy, K. Kumar and C. Arora, "Study of Consumer behavior towards online food delivery," Our Heritage, vol. 67, no. 2, pp. 20147-2058, July- December 2019.

6. M. A. Bhotvawala, H. Balihallimath, N. Bidichandani and M. Khond, "Growth of Food Tech: A Comparative Study of Aggregator Food Delivery Services in India," in International Confrence on Industria Engineering and Operations Management Detroit, Michigan, 2016.

7. M. Joao Chorneukar, "To Study the Consumer Perceptions of Electronic Food Ordering," Bangalore, 2014.

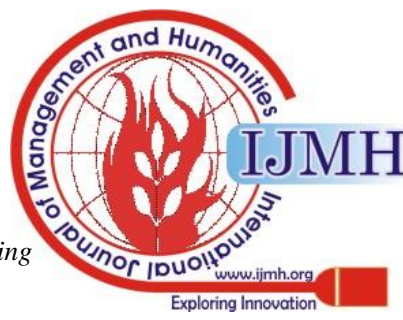


8. R. Malhotra and J. Singh, "To Study the Demand Drivers for Growth of Food Delivery Business in India Through Online Apps and Its Effect on Indian Restaurant Business," Our Heritage, vol. 68, no. 30, pp. 12547-12554, February 2020.

9. N. M P and S. Vivek, "Factors Which Influence the Customers to Show Stickiness Towards Online Food Delivering Provider," International Journal of Recent Technology and Engineering, vol. 8, no. 1, pp. 978-982, May 2019.

10. Beliya, R. Kujur, M. Verma, K. V. Nagwanshi, S. Sahu, N. Uikey and A. A. Bhat, "Satisfaction of Consumers By using Online Food Services," International Journal of Humanities and Social Sciences, vol. 8, no. 4, pp. 35-43, Jun-Jul 2019.

\section{AUTHOR'S PROFILE}

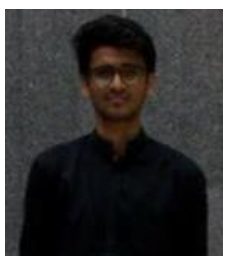

Mr. Mahipal Chandan, is a Bachelor's of Business Administration (BBA) student in NMIMS Anil Surendra Modi School of Comerce, Mumbai. His areas of interest are Finance, stock markets, mutual funds and other related fields. He was a prefect in his school and won various awards in art competitions and stood among top students in school and mathematics and english olympiads. He also won speecha and poetry recital competitions. He is proficient in Microsoft Excel and Python among other skills. He was a part of the college's national level fest, VAAYU as a member of the Fine Arts committee. He aspires to pursue finance from a top b-school in India in the future. Copyright: All rights reserved. 